\title{
The relationship between self-reported received and perceived social support: A meta-analytic review
}

\author{
Mason G. Haber · Jay L. Cohen · Todd Lucas • \\ Boris B. Baltes
}

Published online: 17 February 2007

(C) Springer Science+Business Media, LLC 2007

\begin{abstract}
Social support is broad term encompassing a variety of constructs, including support perceptions (perceived support) and receipt of supportive behaviors (received support). Of these constructs, only perceived support has been regarded as consistently linked to health, and researchers have offered differing assessments of the strength of the received-perceived support relationship. An overall estimate of the received-perceived support relationship would clearly further the dialogue on the relationship between received and perceived support and thus assist in the theoretical development of the field. This study evaluated all available studies using the Inventory of Socially Supportive Behaviors (ISSB; Barrera, Sandler, \& Ramsey, 1981, American Journal of Community Psychology, 9, 435-447) and any measure of perceived social support. Using effect sizes from 23 studies, we found an average correlation of $r=.35, p<.001$. Implications of this estimate for further development of models of social support as well as interventions to enhance social support are discussed.
\end{abstract}

M. G. Haber · J. L. Cohen · B. B. Baltes

Department of Psychology, Wayne State University,

Detroit, MI, USA

\section{T. Lucas}

Center for Behavioral and Decision Sciences in Medicine,

VA Ann Arbor Health Care System \& University of Michigan, Ann Arbor, MI, USA

\section{G. Haber ( $\square)$}

Louis de la Parte Florida Mental Health Institute,

University of South Florida, 13301 Bruce B. Downs Blvd,

Tampa, FL 33612, USA

e-mail: mhaber@fmhi.usf.edu
Keywords Social support - Perceived support . Received support · ISSB

\section{Introduction}

Social support is a broad term encompassing a variety of more specific characteristics of an individual's social world that might promote well-being and/or increase resistance to health problems (Cohen, Gottlieb, \& Underwood, 2000). Social support processes are strongly linked to mental and physical health (House, Landis, \& Umberson, 1988). Although this link has been recognized for some time, limited progress has been made in understanding the more specific mechanisms linking aspects of social support and health (Sarason, Sarason, \& Gurung, 2001). In an effort to better understand more specific social support mechanisms, scholars have described social support as a "meta-construct" consisting of several sub-constructs (Heller \& Swindle, 1983; Vaux, Riedel, \& Stewart, 1987). The present study focuses on two of these subconstructs, received social support and perceived social support. Measures of received social support are designed to assess the specific supportive behaviors that are provided to recipients by their support networks. Perceived social support measures assess recipients' perceptions concerning the general availability of support and/or global satisfaction with support provided (Sarason, Sarason, \& Pierce, 1990). Because received support measures instruct raters to recall specific examples of behavior rather than general impressions, they are thought to more accurately reflect actual support provided by the environment than other types of support measures (Barrera, 1986). 
By contrast, perceived support measures may be subject to individual differences in perceptual, judgment, and memory processes that may result in idiosyncratic perception of supportive events (Lakey \& Drew, 1997), or may be influenced by value judgments regarding the relationship contexts in which the supportive events occur (Sarason, Sarason, \& Pierce, 1995). Recent evidence has emerged that ratings of received support reflect objectively identifiable supportive actions to a much greater extent than do ratings of perceived support. For example, Cohen, Lakey, Tiell, and Neely (2005) demonstrated that inter-observer consensus was much greater for received support than for perceived support.

Although received support measures may more nearly approximate coping assistance from an individual's social environment, a number of authors have suggested that received support may improve outcomes only if it modifies perceived support. This contention is supported by anecdotal observations that received support predicts outcomes less consistently than perceived support (e.g., Barrera, 1986; DunkelSchetter \& Bennett, 1990; Sarason et al., 1990). Metaanalytic data have failed to confirm these impressions, however (DiMatteo, 2004; Smerglia, Miller, \& KortButler, 1999).

Given the hypothesized differences between received and perceived support measures, it is not surprising that the two types of measures have been only weakly related in some studies. For example, in one landmark study of social support, the correlation between received and perceived support was only .01 (Sandler \& Barrera, 1984). Numerous other studies have obtained relatively weak correlations between received and perceived support, leading to contentions in the literature that these constructs are only "mildly" related (Barrera, 1986), or that received and perceived support measures are "typically" related at below .3 (Lakey et al., 2002). Anecdotal observations of such low correlations between received and perceived support measures have contributed to the emergence of social cognitive perspectives on the health effects of social support. According to these perspectives, perceived support is based for the most part on subjective and sometimes idiosyncratic evaluative processes, rather than specific supportive behaviors (Kaul \& Lakey, 2003). Many such processes have been identified. For example, research on person perception suggests that such evaluative judgments are often based on abstract trait concepts, which may be generated quickly, based on very limited samples of actual behavior (Hastie \& Park, 1986; Klein, Loftus, Trafton, \& Fuhrman, 1992). Perceptions of sup- portive behaviors may also be modified by the context in which they occur. Important contextual features may include characteristics of the support provider, characteristics of the provider-receiver relationship (Lakey \& Drew, 1997), and features of the broader cultural environment (Badr, Acitelli, Duck, \& Carl, 2001).

In contrast, some authors have offered a quite different assessment of the strength of the receivedperceived relationship, emphasizing the primacy of specific support behaviors in determining support perceptions. For example, Thoits (1986) suggests that social support processes assist individuals coping efforts in a similar manner to their own coping strategies. In this view, the health-enhancing effects of social support stem directly from the quality of support behavior in the environment, as determined by the objective match between the needs of the support recipient and the type of support provided. Such views, which have been referred to broadly as the stress and coping perspective on social support (Lakey $\&$ Cohen, 2000), suggest that the relationship between received and perceived support should be relatively high, particularly under certain conditions, such as when the support needs match the type of support provided (Cutrona \& Russell, 1990). Similarly, some authors assume that perceptions of support can be assessed through the recall of specific supportive behaviors (Barbee et al., 1993), or have attempted to change levels of perceived support through manipulations that focus on increasing supportive behaviors provided. Although at least one rigorous study has demonstrated that perceived support can be manipulated through altering support levels in the environment (Barrera, Glasgow, McKay, Boles, \& Feil, 2002), a number of others have not (Barrera \& Prelow, 2000; Heller, Thompson, Trueba, Hogg, \& Vlachos-Weber, 1991; Lichtenstein, Glasgow, \& Abrams, 1986).

The stress and coping perspective has clearly dominated the social support field since its inception in the 1970s and has implicitly guided most efforts to manipulate social support in an effort to improve health (Lakey \& Lutz, 1996). Because this perspective as well as the many intervention efforts it informs rest on the assumption that support behaviors and support perceptions are at least moderately correlated, addressing the discrepant views regarding the strength of this relationship is vital to informing future efforts at designing social support interventions. Despite the large number of studies concerned with received and perceived support, to our knowledge, there have been no prior attempts to systematically examine the 
relationship between received and perceived support using meta-analytic procedures. Given the importance of the received-perceived support relationship to social support models, such an analysis is long overdue. To the present time, advocates of the traditional, stress and coping view have had to justify the tenability of interventions to increase received support despite contentions in the literature that received support may have little impact on perceived support (Barrera, 1986). Findings contrary to these impressions, then, would clearly bolster the theoretical basis for these efforts. Alternatively, findings supporting impressions of a weak relationship between received and perceived support measures would strengthen the social cognitive view that perceived support is driven less by supportive behavior and more by aspects of perception that vary across individuals and relationships.

In addition to providing an estimate of the overall relationship between received and perceived support, meta-analytic procedures designed to investigate moderators of an overall relationship could also shed light on how and to what extent support behaviors impact support perceptions. For example, some authors have hypothesized that support perceptions should be more highly associated with support behaviors in cases in which the support recipient is female, due to gender role schemas that emphasize the value of relationships and in turn enhance vigilance for supportive behaviors (Cutrona, Cohen, \& Igram, 1990). Similarly, it is possible that estimates of the relationship between received and perceived support may be higher in circumstances where ratings of perceived support are anchored to specific social relationships, as authors have hypothesized that relationships between support perceptions and support behaviors may be moderated by their relational context (Cutrona \& Russell, 1990; Sarason et al., 2001). Findings in support of these hypotheses could help to better identify the specific mechanisms associated with the effects of support behaviors on support perceptions and could thus assist in predicting times when manipulation of support behavior would be expected to have maximal impact.

Given the daunting number and great diversity of studies on social support and health, we sought ways to focus our meta-analysis to include a manageable number of studies. In particular, we wished to identify a method through which we could focus our efforts on studies that used well-validated methods for received and perceived support measurement. In a previous meta-analytic study of relationships between perceived support and other constructs such as network size, Procidano's (1992) approach to this issue was to select a specific, well-validated measure representing one construct of interest (i.e., perceived support) and to compare that measure to a range of other social support constructs and measures. In the case of the present meta-analysis, we were particularly interested in including studies that adhered to high standards for received support measurement, since some authors have speculated that low received-perceived correlations might be due to deficiencies in the measurement of received support (e.g., Barrera, 1986; Lakey \& Drew, 1997). To that end, the present meta-analysis focused on all studies that have examined the relationship between the Inventory of Socially Supportive Behaviors (ISSB; Barrera, Sandler, \& Ramsey, 1981), a widely used and well-validated measure of received support, and any measure of perceived support. As the vast majority of social support studies assess social support through self-report, only self-report studies were considered.

\section{Method}

\section{Inclusion criteria for studies}

This review was limited to studies that used the ISSB as a measure of received support. As one of the earliest measures of received support, it has been used extensively and has sound psychometric properties (Barrera, 1986). Past research has indicated that the ISSB measures three primary domains of received support: tangible, emotional, and informational (Barrera, 2000). Studies were initially selected if: (a) they had collected both received support and perceived support measures from one or more samples, and (b) the received support measure used was the ISSB. In the course of our search, we identified some studies using the ISSB that measured constructs closely related to perceived support (e.g., loneliness; Stokes, 1985). In the interests of clarity, however, only measures clearly identified by their initial developers as perceived support scales were considered.

\section{Sample of studies}

Literature searches were conducted on several search engines for the period beginning August 1981 (i.e., the date that the ISSB was first published) and ending July 2002. The search was subsequently updated to include all articles published through February 2005. The search engines used in the initial search were: Psychological Abstracts (PsycInfo), Medline (NLM Pubmed version), 
and the Social Science Citation Index (SSCI). Psycinfo and Medline searches were conducted using the following search terms and search term combinations: (a) ISSB; (b) Inventory of Socially Supportive Behaviors; (c) Inventory of Socially Supportive Behaviors and perceived social support; (d) enacted support and perceived social support, and (e) received social support and perceived social support. In addition to retrieving citations associated with these searches, the authors used the SSCI to retrieve all published sources and unpublished dissertations citing the two earliest publications of the ISSB by the original authors of the scale (Barrera et al., 1981; Sandler \& Barrera, 1984). Abstracts for these citations were examined to determine whether multiple social support constructs were measured, and in all cases where multiple social support constructs were mentioned or implied, the corresponding sources were fully reviewed to ascertain whether the ISSB and any perceived support measure were used. In our initial search through July 2002, we found that searches conducted using the SSCI were sufficient to retrieve all articles meeting our criteria, i.e., all hits retrieved using other search methods were redundant with those retrieved through the SSCI searches. Therefore, in updating our search to February 2005, we used only the SSCI search methods.

Based on the review of selected sources, it was determined that a total of 33 sources produced 34 effect sizes that had collected both the ISSB and a perceived support measure. Nine of these effect sizes were not reported in the sources. Although most of the authors of these studies responded to our requests to obtain this data, they were able to provide data for only two of the missing nine effect sizes; thus seven of the nine were excluded from the study. Among the remaining 27 effect sizes, three were eliminated because they provided data identical to that reported in other studies in the meta-analysis (i.e., the same administration of the same measures to the same sample). In each of the three cases that this occurred, we selected one source from each pair that shared the same data (specifically, we retained the source that was published in the higher impact journal as determined by the SSCI). Thus, we arrived at a final sample of 24 effect sizes, culled from 23 sources (22 published journal articles and 1 dissertation). The key characteristics for these effect sizes are summarized in Table 1.

For ten of the 24 effect sizes used in the meta-analysis, the instruments used to measure perceived support contained subscales that clearly pertained to other social support constructs, e.g., items assessing characteristics of the rater's social network, such as network size or embeddedness. Thus, the overall score on such measures was not a "pure" reflection of the perceived support construct. Fortunately, these studies also provided correlations between component subscales and the ISSB. Thus, in these cases, the correlation between the ISSB and the appropriate subscale was used as the effect size. In the perceived social support scale column of Table 1, these subscales are identified by the abbreviation for the parent scale, followed by an abbreviation for the subscale. For example, the "satisfaction" subscale of the Arizona Social Support Interview Scale (ASSIS; Barrera, 1980) is identified as "ASSIS-S."

\section{Variables coded from each study}

Variables from the studies were independently coded by the first three authors. Following independent coding, all disagreements between the authors were resolved through discussion. The coded variables included the following: (a) the Pearson product-moment correlation between the ISSB and the perceived support scale used in the study; (b) the date of the study (i.e., through 1990 or post 1990); (c) the impact of the journal publishing the study on its respective field, as measured by the average number of times $(\leq 1.0$ or $>1.0$ ) that it is cited per year in the Social Science Citation Index (SSCI); (d) sample size; (e) gender composition of the sample (equal male/female or "majority" female, i.e., $>60 \%$ ); (f) sample type, i.e., student or non-student; (g) the specific perceived support scale used (Interpersonal Support Evaluation Scale [ISEL] vs. Social Support Questionnaire- satisfaction subscale [SSQ-S] vs. "other"); (h) whether ratings on perceived support items were "network anchored", i.e., whether they were anchored to specific members of the rater's social network and then aggregated (alternatively, raters could be asked simply to rate each item in terms of the support they received globally); and (i) use of full versus partial versions of the ISSB. All of the variables listed above were included in the moderator analyses.

In addition to these variables, the authors attempted to code the ethnic composition of each sample (\% African American, \% Arab American, \% Asian, \% Latino, \% Native American, \& \% Pacific Islander), as well as the average age and the age range of each sample. However, because many studies did not provide requisite data on age and/or ethnic composition, these variables were not included in the analyses. We also attempted to code for methodological rigor. Our attempts to derive criteria for coding rigor, however, were frustrated by the minimal description of questionnaire administration and other procedures across studies as well as difficulties on achieving consensus 
Table 1 Study characteristics

\begin{tabular}{|c|c|c|c|c|c|c|c|c|c|}
\hline \multirow[t]{2}{*}{ Study } & \multicolumn{9}{|c|}{ Moderators } \\
\hline & $N$ & $r$ & Post 1990 & Impact & $\begin{array}{l}\text { Majority } \\
\text { female }\end{array}$ & $\begin{array}{l}\text { Student } \\
\text { sample }\end{array}$ & PSS scale & $\begin{array}{l}\text { Network } \\
\text { anchored }\end{array}$ & ISSB \\
\hline Barrera and Baca (1990) & 78 & .29 & No & Low & Yes & No (Clinical) & ASSIS-S ${ }^{\mathrm{a}}$ & Yes & Part \\
\hline $\begin{array}{l}\text { Brock, Sarason, Sarason, } \\
\text { and Pierce (1996) }\end{array}$ & 197 & .26 & Yes & Low & Yes & Student & SSQ-S ${ }^{\mathrm{b}}$ & Yes & Full \\
\hline $\begin{array}{l}\text { Brown, Brady, Lent, Wolfert, } \\
\text { and Hall (1987) }\end{array}$ & 99 & .15 & No & High & No & Student & SSI-SS & No & Full \\
\hline Cheng (1999) & 57 & .30 & Yes & High & Yes & Student & ASSR & - & Part \\
\hline Cohen and Hoberman (1983) & 57 & .46 & No & Low & - & Student & ISEL & No & Full \\
\hline $\begin{array}{l}\text { Cohen, McGowan, Fooskas, } \\
\text { and Rose (1984) }\end{array}$ & 92 & .46 & No & Low & No & Student & ISEL & No & Full \\
\hline Cummins (1988) & 112 & .22 & No & Low & No & Student & SPS-G ${ }^{\mathrm{d}}$ & No & Part \\
\hline Emmons and Colby (1995) & 105 & .46 & Yes & High & Yes & Student & ISEL & No & Full \\
\hline Furchner (1998) & 111 & .64 & Yes & Low & No & Student & SSQSR-S & Yes & Full \\
\hline Kaul and Lakey (2003) & 60 & .32 & Yes & Low & Yes & No (Community) & SPS & No & Part \\
\hline Lakey and Cassady (1990) & 101 & .29 & No & High & Yes & Student & ISEL & No & Full \\
\hline Lakey et al. (2002) & 100 & .53 & Yes & High & Yes & No (Community) & QRI-S ${ }^{\mathrm{f}}$ & Yes & Part \\
\hline Lakey, Tardiff, and Drew (1994) & 124 & .49 & Yes & Low & Yes & Student & ISEL & No & Full \\
\hline Newland and Furnham (1999) & 117 & .25 & Yes & High & Yes & Student & ISEL & No & Full \\
\hline Norris and Kaniasty (1996) & 404 & .32 & Yes & High & No & No (Community) & ISEL/SPS $^{\mathrm{g}}$ & No & Part \\
\hline O’Reilly (1995) & 60 & .57 & Yes & Low & No & No (Clinical) & SS-A & No & Full \\
\hline Oritt, Paul, and Behrman (1985) & 146 & .46 & No & Low & - & Student & PSNI & Yes & Full \\
\hline Pretorius (1997) & 166 & .17 & Yes & Low & Yes & Student & SSQ-S & Yes & Full \\
\hline Pretorius and Diedricks (1993) & 242 & .17 & Yes & Low & Yes & Student & SSQ-S ${ }^{b}$ & Yes & Full \\
\hline Sandler and Barrera (1984) & 45 & .01 & No & Low & No & Student & ASSIS-S ${ }^{\mathrm{a}}$ & Yes & Full \\
\hline Sarason et al. (1987) & 217 & .24 & No & High & Yes & Student & SSQ-S ${ }^{b}$ & Yes & Full \\
\hline Swickert et al. (2002) & 99 & .32 & Yes & High & Yes & Student & ISEL & No & Full \\
\hline Waggener and Galassi (1993) & 43 & .34 & Yes & Low & - & No (Community) & SSI & No & Full \\
\hline Waggener and Galassi (1993) & 47 & .22 & Yes & Low & - & No (Community) & SSI & No & Full \\
\hline \multicolumn{10}{|c|}{ Note: Dashes indicate that data were not reported. PSS = Perceived Support Scale } \\
\hline \multicolumn{10}{|l|}{ a ASSIS satisfaction subscale } \\
\hline \multicolumn{10}{|l|}{ b SSQ satisfaction short form } \\
\hline \multicolumn{10}{|l|}{ c SSI subjective satisfaction subscale } \\
\hline \multicolumn{10}{|l|}{ d SPS guidance subscale } \\
\hline \multicolumn{10}{|c|}{ e SSQ Short Record, satisfaction subscale } \\
\hline \multicolumn{10}{|l|}{ f QRI support scale } \\
\hline $\mathrm{g}$ Both ISEL \& SPS items use & & & & & & & & & \\
\hline
\end{tabular}

regarding reasonable criteria for judging study rigor. The impact factor of a given journal as determined by the SSCI is sometimes used as an approximate measure of the journal's methodological quality (Anseel, Duyck, De Baene, \& Brysbaert, 2004). Thus, readers may wish to interpret the journal impact moderator as a proxy for methodological rigor, since articles with higher impact ratings are more likely to be associated with higher quality journals and therefore to have undergone more rigorous peer review.

\section{Meta-analytic procedures}

Hunter and Schmidt (1990) recommended that metaanalytic studies of correlations adjust for attenuation due to measure reliability. In addition to adjusting for attenuation of the overall point estimate, correcting for reliability in the present analyses allowed us to examine the extent to which other properties of measures affected the received-perceived support relationship (i.e., independent of the effects of variation in reliability). Analyses both with and without the recommended adjustment for measure reliability were conducted. As recommended by Hunter and Schmidt (1990), all effect sizes and inverse variance weights were adjusted for attenuation due to error in measurement of perceived and received support, using the coefficient alphas for the ISSB and the perceived support measures selected in each of the studies. In most cases, it was necessary to use the reliability provided in the initial publication of the scale. Specifically, for the ISSB, the average reliability across two administrations of the scale of .93 reported by Barrera et al. (1981) was used. For the SSQ-S, the reliability of .97 reported by 
Sarason, Shearin, Pierce, and Sarason (1987) was used. Sample reliabilities were provided for two of the studies that used the ISEL, including Lakey and Cassady (1990), which reported a coefficient alpha of .91, and Swickert, Rosentretter, Hittner, and Mushrush (2002), which reported a coefficient alpha of .76. The alpha of .77 reported by Cohen and Hoberman (1983) was used for the ISEL in the remaining cases. The average reliability reported for perceived support measures in the "other" category was .86 .

All meta-analytic procedures including calculations of the overall point estimate and homogeneity analyses were conducted with the Comprehensive Meta-analysis (Bornstein \& Rothstein, 1998) computer program using a fixed effects model. Prior to calculating the overall effect size, outlier analyses of both corrected and uncorrected effect sizes were conducted by examining the distribution of standardized correlations ( $z$-scores). Using a cutoff of $z= \pm 3.29$, there were no observed outliers in either set of effect sizes. Overall point estimates with and without reliability correction were calculated using the weighted mean of $z$-transformed product moment coefficients, as recommended by Lipsey and Wilson (2001). Homogeneity tests were performed for both sets of effect sizes using the ANOVAanalog method (Hedges \& Olkin, 1985). This method analyzes categories of studies defined by selected study qualities (moderators). Between-class effects are evaluated using the $\mathrm{Q}_{\mathrm{b}}$ statstic, which has a chi-square distribution with $k-1$ degrees of freedom (where $k$ is the number of classes). Homogeneity of effect sizes within each class is estimated by $Q_{\mathrm{w}}$, which also has a chisquare distribution with $n-1$ degrees of freedom (where $n$ is the number of effect sizes within each class). Alpha level was set at $p<.05$ for all analyses.

\section{Results}

Prior to the reliability correction, the overall Pearson correlation between the ISSB (received support) and measures of perceived support was $r=.32$, with a $95 \%$ confidence interval of $r=.30$ to $r=.34$. The overall correlation following reliability correction was $r=.35$, with a $95 \%$ confidence interval of $r=.32$ to $r=.39$. Effect sizes were found to be heterogeneous both prior to and following reliability correction (prior to reliability correction, $\chi^{2}(23)=147.343, p<.001$; following reliability correction, $\left.\chi^{2}(23)=178.5, p<.001\right)$.

Results of moderator analyses preceding and following correction yielded somewhat different results. Although sample type was significant prior to reliability correction, such that student samples produced lower correlations than other (clinical and community) samples, $\chi^{2}(1)=4.00, p<.05$, this moderator did not remain significant following reliability correction, $\chi^{2}$ $(1)=1.89$, ns. Thus, the lower correlations found among studies using student samples could be the result of the lower reliability of the perceived support scales in those studies. Gender composition was found to be significant in the uncorrected analyses, $\chi^{2}$ (1) $=4.54, p<.05$, in the manner opposite to the predicted pattern, such that studies with a majority $(>60 \%)$ of female participants produced lower correlations (pooled $r=.29$ ) than those in which smaller proportions of the sample were female (pooled $r=.35$ ). Correction for reliability reduced this to a trend level finding, however, $\chi^{2}(1)=3.82, p<.10$. Conversely, whether correlations were "network anchored" (i.e., whether or not raters were asked to rate items for individuals or for their entire network; see Method section), was a trend level finding prior to correction, $\chi^{2}(1)=2.81, p<.10$, but became significant if reliability correction was applied, $\chi^{2}(1)=4.27$, $p<.05$. Once again, the direction of the effect was not consistent with predictions based on theory; specifically, perceived support ratings anchored to specific network members produced lower correlations with the ISSB (pooled $r=.31$ ) than those that were not anchored (pooled $r=.37$ ).

Only one moderator, scale type, (i.e., ISEL vs. SSQ$\mathrm{S}$ vs. other) was significant both prior to, $\chi^{2}(2)=15.80$, $p<.001$ and following artifact adjustment, $\chi^{2}$ $(2)=26.55, p<.001$. Table 2 shows the reliability corrected mean correlations for each of the perceived support scales as well as post hoc comparisons between means. As shown in Table 2, post hoc comparisons indicated that the received-perceived support correlations produced by studies using the ISEL, the SSQ, and "other" perceived support scales were all significantly different from one another, such that received-perceived support correlations produced by the ISEL (pooled $r=.45$ ) were the highest, correlations produced by the SSQ (pooled $r=.28$ ) were the lowest,

Table 2 Comparisons of ISSB correlations across perceived support scales

\begin{tabular}{lcccc}
\hline $\begin{array}{l}\text { Comparison } \\
\text { (I vs. J) }\end{array}$ & \multicolumn{2}{l}{ Pooled $r$} & \multicolumn{2}{l}{$\begin{array}{l}\text { Difference } \\
(\mathrm{I}-\mathrm{J})^{\mathrm{a}}\end{array}$} \\
\cline { 2 - 4 } & $\mathrm{I}$ & $\mathrm{J}$ & & $\chi^{2}$ \\
\hline ISEL vs. SSQ & .45 & .28 & .17 & $26.38^{* * * *}$ \\
ISEL vs. other & .45 & .35 & .10 & $9.51^{* *}$ \\
Other vs. SSQ & .35 & .28 & .08 & $7.10^{*}$ \\
\hline a Difference rounded to nearest & $.01, * p<.05 ; * * p<.01 ;$ \\
$* * * p<.001$ & & &
\end{tabular}


and correlations produced by the "other" scales (pooled $r=.35$ ) fell in between. $Q_{\mathrm{w}}$ tests representing variance within each of these categories were significant for all three scales (for the ISEL, $\chi^{2}(6)=23.84$, $p<.01$; for the SSQ-S, $\chi^{2}(4)=63.37, p<.001$; for the "other" scales, $\left.\chi^{2}(11)=64.74, p<.01\right)$, suggesting that the scales represented by each category are capable of producing a variety of estimates.

\section{Discussion}

The primary purpose of this meta-analytic review was to establish a point estimate for the relationship between received and perceived support. Compelling arguments have been made elsewhere for basing social support interventions on sound theory and empirically supported models (Lakey \& Cohen, 2000). Establishing an overall point estimate is an important first step in this process. An examination of the strength of the received-perceived support relationship across studies as well as factors that might influence the strength of this relationship contributes to the dialogue on social support processes and the mechanisms by which they operate. More specifically, these data serve to address disagreements in the literature regarding how the relationship between received and perceived support should be understood, since these disagreements appear to be based to some extent on different assessments of the overall strength of this relationship. Although the point estimate derived in the present study does not reflect correlations found between received support measures other than the ISSB and perceived support measures, we believe that this estimate is a useful starting point for estimating the strength of the association of the underlying constructs.

While most social scientists would regard the overall point estimates in this review of $r=.32$ (prior to reliability correction) and .35 (following reliability correction) as interpretable and important effect sizes, it is unlikely that estimates of this size can support the traditional view that received support is the primary constituent factor in perceived support. Effects of this size, which represent only $10-15 \%$ of the total variance in the combined measures, clearly indicate that other factors must be incorporated in social support models. Social-cognitive theories attempt to capture this complexity by attempting to describe how the same, objectively identifiable support behaviors may be interpreted differently by different individuals, due to factors such as the characteristics of the individual perceiver, characteristics of the support provider, and characteristics of the provider-receiver relationship (Lakey, McCabe, Fisicaro, \& Drew, 1996). Factors associated with the larger social and cultural context of specific supportive interactions may affect support judgments as well (Badr et al., 2001). Ecologically oriented theories describing these factors complement rather than conflict with theories that describe cognitive, judgment, and perceptual processes, since both approaches to understanding social support challenge the notion that support perceptions are primarily determined by specific, objectively identifiable events (Procidano, 1997).

The considerable range of received-perceived support correlations in the meta-analysis underscores the importance of determining which factors moderate the relationship between received and perceived support. Unfortunately, results of the moderator analyses mostly failed to identify moderators consistently across analyses prior to and following reliability correction of effect sizes. It could be argued that findings following reliability correction are more robust, since artifact-corrected moderator analyses have been shown to yield somewhat more conservative findings than analyses that do not correct for artifacts, and since the effects of moderators prior to reliability correction may be confounded with measure reliability (Hunter \& Schmidt, 1990). Due to disagreement in the literature regarding how measurement artifacts should be handled, however (e.g., James, Demaree, \& Mulaik, 1986), lack of consistency across uncorrected and corrected results presents problems for interpretation of these moderators, regardless of whether the significant findings were shown before or after the correction. Three of the four moderators significantly affected the strength of the received-perceived support relationship in only one of the two sets of analyses. More specifically, prior to reliability correction, studies that employed student samples and studies that contained mostly female participants tended to show lower correlations between received and perceived support. Following reliability correction, studies that required participants to anchor perceived support ratings to network members produced lower correlations than those that did not have this requirement. Despite their inconsistency, it is noteworthy that results for gender and network anchoring were opposite of those that were predicted based on the literature, since these factors were expected to result in stronger received-perceived support relationships. Thus, although inconsistent, the direction of findings where present failed to support theories that female gender role schemas and/or priming of specific relationship contexts strengthen the relationship 
between received and perceived support. Interpretation of the significant result for sample type (i.e., student vs. non-student) is even more problematic than interpretation of the gender and network anchoring findings for three reasons: (1) no specific prediction was made regarding the expected direction of the effect; (2) unlike the findings for gender and network anchoring, which were at least marginally significant across uncorrected and corrected sets of effects (i.e., $p<.10$ ), the significance of the finding for sample type did not approximate our alpha level of $p<.05$ in one of the two sets of analyses; and (3) because insufficient studies existed to divide the "non-student" category further (e.g., into clinical and community samples), the samples that were included in this category may be incompatible on the dimension represented by the student vs. non-student comparison.

The one moderator that consistently showed a significant relationship with effect sizes, scale type, suggested that the selection of perceived support scale may have an interpretively significant impact on received-perceived support correlations. For example, the (post-correction) $r=.45$ estimate from studies that used the ISEL suggests that the relationship between received and perceived support accounts for between $15 \%$ and $20 \%$ of the combined variance of measures of both constructs, whereas the .28 estimate from studies using the SSQ-S suggests that the relationship is considerably smaller, ranging between $5 \%$ and $10 \%$. It is possible to speculate on specific factors that might underlie the apparent discrepancy between point estimates provided by the measures. Distinct factors representing satisfaction with different types of support behavior on the ISEL (Cohen \& Hoberman, 1983) suggest that this instrument may have broader coverage than the SSQ-S, which has only one factor (Sarason, Levine, Basham, \& Sarason, 1983). It could be argued that because of the ISEL's wider coverage of different types of support behavior, the scale might be more prone to eliciting ratings based on specific examples; thus, higher correlations provided by the ISEL could be due to a tendency shared with received support measures to prompt consideration of specific types of support behavior. The small number of studies within the ISEL and SSQ classes and the significant heterogeneity of variance within these classes, however, suggest that inclusion of future studies with these instruments might alter estimates of relationships between these measures and the ISSB. Thus, estimated effect sizes for each scale could change if more studies using each of these measures were conducted and analyzed along with data from the present sample.
Limitations and future directions

The foremost limitation of the present study was our decision to restrict the sample to studies using the ISSB. Although the resulting sample was sufficient for our primary objective of establishing a preliminary point estimate of the received-perceived social support relationship, it was clearly less than ideal for purposes of moderator testing. Specifically, the small number of studies included in the present meta-analysis resulted in poor power to detect significant moderators. This is a particularly important limitation, given the number of "trend" level findings that emerged in moderator analyses, which resulted in inconsistent results across uncorrected and corrected datasets and complicated interpretation. In addition to the power limitations that resulted from limiting the meta-analysis to a relatively small group of studies, the choice to select only studies using the ISSB also precluded analysis of any variation in the received-perceived support relationship across received support measures. While the ISSB measure is possibly the best validated and most widely used received social support measure, other well-validated and established measures of received support are also available (e.g. Dunkel-Schetter \& Bennett, 1990). An extension of the present study to include studies using other measures of received social support may be necessary, both to further validate the estimated relationship between received and perceived support and to improve our understanding of the factors that moderate that relationship.

Other limitations of our meta-analysis were due to the present limitations of the social support literature. Among these, one important limitation is the heavy reliance in the literature on self-report methods. The studies in the present meta-analysis utilized self-report exclusively in their measurement of social support constructs, including the construct of received support, a fact that precluded examination of the rater (e.g., support provider vs. support recipient vs. observer), as a possible moderator of the strength of the relationship between received and perceived support ratings. Both received and perceived measures are, to some degree, measures of support perceptions, a fact that Barrera (1986) recognized when he termed received support measures "perceived-received". All self-report measures, including received support measures, rely on the accurate reporting of information by the social support recipient and are therefore subject to influence by perceptual factors. Several aspects of the ISSB address this issue by increasing the behavioral specificity of the rating process. For example, raters are typically instructed to consider only limited and recent periods of 
time (typically, the last 30 days), and to enumerate specific behaviors. There is some evidence to suggest that such efforts to improve the objectivity of the ISSB as well as other received support measures have been effective. For example, recently, Cohen et al. (2005) demonstrated that agreement between ISSB ratings of support providers and recipients is very high $(r=.75)$, and furthermore, that agreement is significantly higher on supportive behaviors than is agreement on perceived support. Nonetheless, shared methods variance across received and perceived support constructs due to exclusive use of self-report methodology likely inflated the estimate of the received-perceived support relationship in this study. Future research on social support should consider multiple methods of data collection, wherever possible.

Another issue related to the current state of the social support literature is the lack of consensus regarding which of the numerous and diverse constructs related to social support are vital to measure in any given study. Although the diversity of approaches to social support measurement contributes to the richness of the literature, inadequate integration of these approaches undermines efforts to summarize the literature in a systematic manner. Many of our efforts to identify theory-oriented moderators to explain heterogeneity among point estimates were unsuccessful, as such variables are typically measured in only a small subset of studies on social support. For example, we would have liked to address the issue of possible moderation of the received-perceived support relationship by person-environment fit (i.e., between the support behavior and the needs/desires of the recipient); however, most studies of received and perceived support do not consider this issue (Vaux, 1988). Given that only a minority of studies of social support consider the issue of person-environment fit, examination of its impact on the relationship between received and perceived support through meta-analytic procedures was not possible.

In addition to difficulties examining moderation by other social support constructs such as fit, we were surprised at the difficulties we had gathering more basic information such as demographics from studies in the sample (e.g., the average age and/or age range of the sample of raters and information pertaining to ethnicity). Because an insufficient number of studies included this information, our analysis of demographic moderators was limited to one variable (i.e., gender). We recommend that future social support researchers consistently include basic descriptive information concerning their sample, such as age and ethnicity, so that the possible impact of these factors on relation- ships between social support constructs can be evaluated. Finally, the bias in the social support literature toward using the most convenient sample type (i.e. university student) prevented us from examining the effect of different sample types on effect sizes in the manner we would have liked. In particular, we would have liked to examine possible differences between point estimates derived from student and clinical samples or between student and community samples; given the small number of studies using non-students, however, we could only compare student samples to all other sample types combined. Application of sophisticated social support measurement (i.e., measurement of multiple social support constructs) to research with non-student populations is clearly an important direction for social support research in the future.

\section{Future meta-analyses?}

The proliferation of diverse approaches to social support measurement has resulted in a large number of potential relationships to examine involving social support measures and/or social support constructs. It is unlikely that any given study will be able to incorporate more than a few such approaches. Further integrative efforts such as the present meta-analysis are needed to identify how strongly different social support constructs are related. An obvious next step in better understanding the relationship between received and perceived support, for example, would be to conduct a larger meta-analysis in which additional measures of received support would be included. Given the extensive literature including measures of received support, this would clearly be an ambitious undertaking, but would provide a more authoritative point estimate.

In addition to an expansion of the present metaanalysis, meta-analyses examining other relationships between social support constructs or between these constructs and outcomes could be conducted as well. For example, contentions in the literature that perceived support is more highly related to outcomes than received support could be tested by meta-analyses comparing the predictive abilities of received and perceived social support. The limited attempts to address these issues in prior meta-analyses have not, in fact, supported the contention that perceived support is more highly predictive than received or other types of social support; however, one of these meta-analyses (DiMatteo, 2004) was not specifically designed to address the issue, and the other (Smerglia, Miller, \& Kort-Butler, 1999) used vote-counting as its method of aggregation, which has been shown to be a relatively 
insensitive method in comparison to meta-analytic procedures such as those used in the present study (Hedges \& Olkin, 1985). It would also be helpful to assess relationships between received support and other support constructs such as network size or embeddedness and/or relationships between perceived support and these other constructs. Still other issues that could be examined in future meta-analyses would be the level of convergence of support ratings across raters (e.g., relationships between a given support construct as rated by a support recipient with the same support construct rated by the support provider), relationships between retrospective ratings and ratings made contemporaneously (through diary or other methods), or relationships between ratings of different types of perceived or received support (e.g., instrumental, emotional, etc.). Ultimately, efforts at examining such relationships may increase the level of consensus concerning which aspects of social support are most critical to the meta-construct and how they are related to one another. In turn, we anticipate such improved understanding would lead to more focused efforts to improve health outcomes through enhancing social support.

Acknowledgements We would like to thank Brian Lakey and Ardis Hanson for their helpful assistance with this project.

\section{References}

*References marked with an asterisk indicate studies included in the meta-analysis.

Anseel, F., Duyck, W., De Baene, W., \& Brysbaert, M. (2004). Journal impact factors and self-citations: Implications for psychology journals. American Psychologist, 59, 49-51.

Badr, H., Acitelli, L. K., Duck, S., \& Carl, W. J. (2001). Weaving social support and relationships together. In B. Sarason \& S. Duck (Eds.), Personal relationships: Implications for clinical and community psychology (pp. 1-14). West Sussex, UK: Wiley.

Barbee, A. P., Cunningham, M. R., Winstead, B. A., Derlega, V. J., Gulley, M. R., Yankeelov, P. A., et al. (1993). Effects of gender role expectations on the social support process. Journal of Social Issues, 49, 175-190.

Barrera, M. Jr. (1980). A method for the assessment of social support networks in community survey research. Connections, 3, 8-13.

Barrera, M. Jr. (1986). Distinctions between social support concepts, measures and models. American Journal of Community Psychology, 14, 413-455.

Barrera, M. Jr. (2000). Social support research in community psychology. In J. Rappaport \& E. Seidman (Eds.), Handbook of community psychology (pp. 215-246). New York: Plenum.

*Barrera, M. Jr., \& Baca, L. M. (1990). Recipient reactions to social support: Contributions of enacted support, conflicted support, and network orientation. Journal of Social and Personal Relationships, 7, 541-551.

Barrera, M., Glasgow, R. E., McKay, H. G., Boles, S. M., \& Feil, E. G. (2002). Do internet-based support interventions change perceptions of social support? An experimental trial of approaches for supporting diabetes self-management. American Journal of Community Psychology, 30, 637-654.

Barrera, M., \& Prelow, H. (2000). Interventions to promote social support in children and adolescents. In D. Cicchetti, J. Rappaport, I. N. Sandler, \& R. P. Weissberg (Eds.), The promotion of wellness in children and adolescents (pp. 309339). Washington, DC: CWLA Press.

Barrera, M., Sandler, I. N., \& Ramsey, T. B. (1981). Preliminary development of a scale of social support: Studies on college students. American Journal of Community Psychology, 9, 435-447.

Bornstein, M., \& Rothstein, H. (1998). Comprehensive meta analysis. New Jersey: Biostat.

*Brock, D. M., Sarason, I. G., Sarason, B. R., \& Pierce, G. R. (1996). Simultaneous assessment of perceived global and relationship specific support. Journal of Social and Personal Relationships, 13, 143-152.

*Brown, S. D., Brady, T., Lent, R. W., Wolfert, J., \& Hall, S. (1987). Perceived social support among college students: Three studies of the psychometric characteristics and counseling uses of the Social Support Inventory. Journal of Counseling Psychology, 34, 337-354.

*Cheng, C. (1999). Gender-role differences in susceptibility to the influence of support availability on depression. Journal of Personality, 67, 439-467.

Cohen, S., Gottlieb, B. H., \& Underwood, L. G. (2000). Social relationships and health. In S. Cohen, L. Underwood, \& B. H. Gottlieb (Eds.), Social support measurement and intervention: A guide for health and social scientists (pp. 3-25). New York: Oxford University Press.

Cohen, J. L., Lakey, B., Tiell, K., \& Neely, L. C. (2005). Recipient-provider agreement on enacted support, perceived support, and provider personality. Psychological Assessment, 17, 375-378.

*Cohen, L. H., McGowan, J., Fooskas, S., \& Rose, S. (1984). Positive life events and social support and the relationship between life stress and psychological disorder. American Journal of Community Psychology, 12, 567-587.

*Cohen, S., \& Hoberman, H. M. (1983). Positive events and social supports as buffers of life change stress. Journal of Applied Social Psychology, 13, 99-125.

*Cummins, R. C. (1988). Perceptions of social support, receipt of supportive behaviors, and locus of control as moderators of the effects of chronic stress. American Journal of Community Psychology, 16, 685-700.

Cutrona, C. E., Cohen, B. B., \& Igram, S. (1990). Contextual determinants of perceived supportiveness of helping behaviors. Journal of Social and Personal Relationships, 7, 553562.

Cutrona, C. E., \& Russell, D. W. (1990). Type of social support and specific stress: Toward a theory of optimal matching. In B. R. Sarason, I. G. Sarason, \& G. R. Pierce (Eds.), Social support: An interactional view (pp. 319-366). New York: John Wiley.

DiMatteo, M. R. (2004). Social support and patient adherence to treatment: A meta-analysis. Health Psychology, 23, 207-218.

Dunkel-Schetter, C., \& Bennett, T. L. (1990). Differentiating the cognitive and behavioral aspects of social support. In B. R. Sarason, I. G. Sarason, \& G. R. Pierce (Eds.), Social support: An interactional view (pp. 267-296). New York: Wiley. 
*Emmons, R. A., \& Colby, P. M. (1995). Emotional conflict and well-being: Relation to perceived availability, utilization, and observer reports of social support. Journal of Personality and Social Psychology, 68, 947-959.

*Furchner, A. (1998). Type-A behavior pattern and social support. Unpublished doctoral dissertation.

Hastie, R., \& Park, B. (1986). The relationship between memory and judgement depends on whether the judgement is memory-based or on-line. Psychological Review, 93, 258268.

Hedges, L. V., \& Olkin, I. (1985). Statistical methods for metaanalysis. Orlando FL: Academic Press.

Heller, K., \& Swindle, R. W. (1983). Social networks, perceived social support, and coping with stress. In R. D. Felner, L. A. Jason, J. N. Moritsugu, \& S. S. Farber (Eds.), Preventive psychology: Theory, research and practice (pp. 87-103). New York: Pergamon.

Heller, K., Thompson, M. G., Trueba, P. E., Hogg, J. R., \& Vlachos-Weber, I. (1991). Peer support telephone dyads for elderly women: Was this the wrong intervention? American Journal of Community Psychology, 19, 53-74.

House, J. S., Landis, K. R., \& Umberson, D. (1988). Social relationships and health. Science, 241, 540-545.

Hunter, J. E., \& Schmidt, F. L. (1990). Methods of meta-analysis: Correcting error and bias in research findings. Newbury Park, CA: Sage.

James, L. R., Demaree, R. G., \& Mulaik, S. A. (1986). A note on validity generalization procedures. Journal of Applied Psychology, 71, 440-450.

*Kaul, M., \& Lakey, B. (2003). Where is the support in perceived support? The role of generic relationship satisfaction and enacted support in perceived support's relation to low distress. Journal of Social and Clinical Psychology, 22, 5978.

Klein, S. B., Loftus, J., Trafton, J. G., \& Fuhrman, R. W. (1992). Use of exemplars and abstractions in trait judgments: A model of trait knowledge about the self and others. Journal of Personality and Social Psychology, 63, 739-753.

*Lakey, B., Adams, K., Neely, L., Rhodes, G., Lutz, C. J., \& Sielky, K. (2002). Perceived support and low emotional distress: The role of enacted support, dyad similarity, and provider personality. Personality and Social Psychology Bulletin, 28, 1546-1555.

*Lakey, B., \& Cassady, P. B. (1990). Cognitive processes in perceived social support. Journal of Personality and Social Psychology, 59, 337-343.

Lakey, B., \& Cohen, S. (2000). Social support theory and measurement. In S. Cohen, L. G. Underwood, \& B. H. Gottlieb (Eds.), Social support measurement and intervention: A guide for health and social scientists (pp. 29-52). London, UK: Oxford University Press.

Lakey, B., \& Drew, J. B. (1997). A social-cognitive perspective on social support. In G. R. Pierce, B. Lakey, I. G. Sarason, \& B. R. Sarason (Eds.), Sourcebook of theory and research on social support and personality. New York: Plenum.

Lakey, B., \& Lutz, C. J. (1996). Social support and preventive and therapeutic interventions. In G. R. Pierce, B. R. Sarason, \& I. G. Sarason (Eds.), Handbook of social support and the family (pp. 435-465). New York: Plenum.

Lakey, B., McCabe, K. M., Fisicaro, S. A., \& Drew, J. B. (1996). Environmental and personal determinants of support perceptions: Three generalizability studies. Journal of Personality and Social Psychology, 70, 1270-1280.

*Lakey, B., Tardiff, T. A., \& Drew, J. B. (1994). Negative social interactions: Assessment and relation to social support, cognition, and psychological distress. Journal of Social and Clinical Psychology, 13, 42-62.

Lichtenstein, E., Glasgow, R. E., \& Abrams, D. (1986). Social support in smoking cessation: In search of effective interventions. Behavior Therapy, 17, 607-619.

Lipsey, M. W., \& Wilson, D. B. (2001). Applied social research methods series: Vol 49. Practical meta-analysis. New York: Sage.

*Newland, J., \& Furnham, A. (1999). Perceived availability of social support. Personality and Individual Differences, 27, 659-663.

*Norris, F. H., \& Kaniasty, K. (1996). Received and perceived social support in times of stress: A test of the social support deterioration deterrence model. Journal of Personality and Social Psychology, 71, 498-511.

*O'Reilly, B. K. (1995). The Social Support Appraisals Scale: Construct validation for psychiatric inpatients. Journal of Clinical Psychology, 51, 37-42.

*Oritt, E. J., Paul, S. C., \& Behrman, J. A. (1985). The Perceived Support Network Inventory. American Journal of Community Psychology, 13, 565-582.

*Pretorius, T. B. (1997). The quality of dyadic relationships and the experience of social support. South African Journal of Psychology, 27, 171-174.

*Pretorius, T. B., \& Diedricks, M. (1993). A factorial investigation of the dimensions of social support. South African Journal of Psychology, 23, 32-35.

Procidano, M. E. (1992). The nature of perceived social support: Findings of meta-analytic studies. In C. D. Spielberger \& J. N. Butcher (Eds.), Advances in personality assessment (Vol. 9). Hillsdale, NJ: Erlbaum.

Procidano, M. E. (1997). Assessing perceived social support: The importance of context. In G. R. Pierce, B. Lakey, I. G. Sarason, \& B. R. Sarason (Eds.), Sourcebook of social support and personality (pp. 93-106). New York: Plenum.

*Sandler, I. N., \& Barrera, M. Jr. (1984). Toward a multimethod approach to assessing the effects of social support. American Journal of Community Psychology, 12, 37-52.

Sarason, I. G., Levine, H. M., Basham, R. B., \& Sarason, B. R. (1983). Assessing social support: The Social Support Questionnaire. Journal of Personality and Social Psychology, 44, 127-139.

Sarason, B. R., Sarason, I. G., \& Gurung, R. A. R. (2001). Close personal relationships and health outcomes: A key to the role of social support. In B. Sarason \& S. Duck (Eds.), Personal relationships: Implications for clinical and community psychology (pp. 15-41). West Sussex, UK: Wiley.

Sarason, B. R., Sarason, I. G., \& Pierce, G. R. (1990). Traditional views of social support and their impact on assessment. In B. R. Sarason, I. G. Sarason, \& G. R. Pierce (Eds.), Social support: An interactional view (pp. 9-25). New York: Wiley.

*Sarason, B. R., Shearin, E. N., Pierce, G. R., \& Sarason, I. G. (1987). Interrelations of social support measures. Journal of Personality and Social Psychology, 52, 813-832.

Sarason, I. G., Sarason, B. R., \& Pierce, G. R. (1995). Stress and social support. In S. E. Hobfoll \& M. W. de Vries (Eds.), Extreme stress and communities: Impact and Intervention (pp. 179-197). New York: Plenum.

Smerglia, V. L., Miller, N. B., \& Kort-Butler, L. (1999). The impact of social support on women's adjustment to divorce: A literature review and analysis. Journal of Divorce and Remarriage, 32, 63-87.

Stokes, J. P. (1985). The relation of social network and individual difference variables to loneliness. Journal of Personality and Social Psychology, 4, 981-990. 
*Swickert, R. J., Rosentreter, C. J., Hittner, J. B., \& Mushrush, J. E. (2002). Extraversion, social support processes, and stress. Personality and Individual Differences, 32, 877-891.

*Thoits, P. A. (1986). Social support as coping assistance. Journal of Consulting and Clinical Psychology, 54, 416-423.

Vaux, A. (1988). Social support: Theory, research, and intervention. New York: Praeger.
Vaux, A., Riedel, S., \& Stewart, D. (1987). Modes of social support: The Social Support Behaviors (SS-B) Scale. American Journal of Community Psychology, 15, 209-237.

*Waggener, N. M., \& Galassi, J. P. (1993). The relation of frequency, satisfaction, and type of socially supportive behaviors to psychological adjustment in marital separation. Journal of Divorce and Remarriage, 21, 139-159. 